\title{
NSF ATE MPEC Midwest Photonics Education Center
}

\section{Mr. Greg Kepner, Midwest Photonics Education Center}

GREG KEPNER, M. Ed., is the Department Chair for Advanced Manufacturing Technology programs at Indian Hills Community College. Greg serves as the Principal Investigator and Director of MPEC, the Midwest Photonics Education Center, a regional NSF-ATE center. Greg previously served as a CoPrincipal Investigator for OP-TEC, the NSF-ATE National Center for Optics and Photonics Education. He has administrative responsibility for the leadership of the manufacturing technology programs at IHCC. He has served as Industrial Technology Coordinator and has taught automation, robotics, and electronics. He developed an Early College program in which high school students earn post-secondary credits towards an AAS degree in Lasers, Robotics, or Electronics Engineering. He has previously worked as a Senior Field Service Engineer in semiconductor manufacturing and is currently serving on the boards of the Iowa Association of Career and Technical Education and the Iowa Industrial Technology Education Association.

\section{Dr. Anca L. Sala, Baker College, Flint}

Dr. Anca L. Sala is Professor and Dean of Engineering and Computer Technology at Baker College of Flint. In addition to her administrative role she is involved with development of new engineering and technology programs and curriculum, improving teaching and assessment of student learning, assessment of program outcomes and objectives, and ABET accreditation. She is a founding member of Mi-Light Michigan Photonics Cluster, and is active in the ASEE, ASME, and OSA professional societies serving in various capacities. 


\title{
NSF ATE MPEC Midwest Photonics Education Center
}

\begin{abstract}
The International Year of Light was celebrated in 2015 with events all over the world highlighting the strategic importance of photonics and light-based technologies. As an enabling technology, photonics plays a key role in fields as diverse as manufacturing, health and medicine, communications, defense, and energy. A new advanced manufacturing institute dedicated to Integrated Photonics was also announced in 2015 which has attracted the highest public and private investment to date.
\end{abstract}

Focusing on the education of technicians, the Midwest Photonics Education Center was established in 2014 as an NSF ATE supported regional center. It brings together nine colleges and universities and numerous industry partners from nine Midwest states. Its main mission is to develop and grow two year photonics technician education programs to prepare the highly skilled workforce the photonics industry needs. The goals of the Center are: 1) Establish education programs and strategies to address industry needs for photonics technicians, 2) Provide national leadership for technician education in laser-assisted advanced manufacturing, 3) Strengthen educational institutions' ability to recruit, train and advance photonics students including women, minorities and veterans, 4) Collaborate with partner educational institutions and employers to promote photonics in the K-14 space to fill the student "pipeline", 5) Develop customized on-site photonics education workshops and provide to companies and colleges, and 6) Evaluate educational materials and share best practices.

Accomplishments during the first year since the Center was established include: mentoring and advising several colleges interested in adding dedicated photonics programs and infusing photonics courses in existing curricula, surveying 950 employers to determine their education and training needs in the photonics area, delivering outreach events to $8000+\mathrm{K}-12$ students involving hands-on exploration of lasers and optics, providing professional development to faculty, participating in training and subsequently developing a recruiting and retention plan for females and minorities into the photonics technology field, and giving presentations about best practices in photonics technician education at several conferences. Next steps include setting up a laser assisted manufacturing laboratory at Indian Hills Community College and developing the associated curriculum to serve as a model for colleges in the Midwest interested in teaching this advanced manufacturing technology.

\section{Introduction}

Photonics is the science and technology of generating, controlling, and detecting photons, which are particles of light. Photonics technologies are rapidly expanding through wide-scale applications in manufacturing and materials processing, defense and homeland security, renewable energy, telecommunications, diagnostic and therapeutic medical equipment, environmental monitoring, optoelectronics/nanotechnology and solid state lighting. The strategic importance of photonics and light-based technologies was recognized by the United Nations when adopting year 2015 as the International Year of Light, which was celebrated with hundreds of events all over the world ${ }^{1}$. 
A new advanced manufacturing institute dedicated to Integrated Photonics was also announced in 2015. The American Institute for Manufacturing Integrated Photonics (AIM Photonics) ${ }^{2}$ is an industry driven public-private partnership that is looking to emulate the dramatic successes experienced by the electronics industry over the past 40 years and transition key lessons, processes, and approaches to the photonic integrated circuit (PIC) industry. It is notable that this institute has attracted the highest public and private investment to date, estimated at $\$ 610$ million.

Year 2015 was very successful in raising public awareness about the field of photonics and in dedicating important resources to its accelerated growth and expansion. To arrive at this point, various organizations understood the importance of the field many years ago and have since been working to promote its development. Workforce development is one of the critical elements that is needed to support the growth of the industry. The mission of the NSF funded National Center for Optics and Photonics Education, OP-TEC ${ }^{3}$, is to increase the supply of well-educated Photonics Technicians by building and strengthening the capacity and quality of photonics education in U.S. two-year colleges. OP-TEC has conducted national surveys to gauge the photonics industry's needs for technicians. The surveys found that a gap between the number of technicians needed and the number of graduates from two-year photonics technicians programs continues to exist. This finding together with the need for more specialized technician training in the Midwest region, which is heavily dependent on manufacturing, have led to the proposal to establish a photonics education center in the Midwest.

A group of stakeholders including 16 photonics industry representatives, five educators, and two OP-TEC representatives originally met in 2010 and formed a Midwest photonics cluster. As a result of this meeting, new partnerships were formed and plans were made to move forward with the pursuit of a regional center. In 2011, a planning grant (NSF Award \#1104083) was received and utilized to develop the foundation for the creation of the Midwest Photonics Education Center (MPEC). The work of the planning grant included identifying additional educational institutions, partnering with OP-TEC on a national needs assessment for photonics technicians, providing outreach activities to share information and meeting with additional industry representatives to discuss needs and obtain commitments.

The employer demand for qualified photonics technicians nationwide is great and has continued to grow in recent years. In 2012, a national survey was commissioned by OP-TEC and its partners, including Indian Hills Community College (IHCC) with the planning grant, titled "Industry Demand for Two-Year College Graduates in Optics and Photonics Technology." 4 This survey asked 346 U.S. photonics employers about their current and future needs for two-year degreed photonics technicians. The results showed a need for 4,115 new photonics technicians with two-year degrees between 2012 and 2017. In the Midwest, companies projected a need for 214 additional technicians in the next year and 725 technicians from 2012-2017. IHCC only graduates about 20 students per year so the supply of well-educated photonics graduates was not keeping up with demand.

The Midwest Photonics Education Center (MPEC), a National Science Foundation (NSF) funded regional center for Advanced Technological Education (ATE), was established in 2014. The Center's goals are to increase the supply of well-educated photonics technicians in the Midwest, and to serve as the national leader in photonics applications for advanced manufacturing and laser materials processing. 


\section{MPEC goals and objectives}

The MPEC brings together nine colleges and universities and numerous industry partners from nine Midwest states. The states covered by the Center are: Illinois, Indiana, Iowa, Michigan, Minnesota, Missouri, Ohio, Nebraska and Wisconsin. The Midwest region comprises a large manufacturing sector, which is relying more and more on advanced manufacturing methods using lasers and other photonics equipment. At the same time, there is also a growing photonics industry in the Midwest making photonics devices and systems. In the state of Michigan for example, several photonics companies, colleges and universities have formed the Mi-Light Michigan Photonics Cluster ${ }^{5}$ in 2012. Mi-Light is a non-profit organization that aims to expand the industry, attract funding and stimulate innovation in Michigan. Since formation, the Cluster has grown in membership and has attracted the attention of photonics companies even in neighboring states. Industry representatives have been involved with MPEC from its inception.

Indian Hills Community College is the lead college and fiscal agent for MPEC. The MPEC principal educational partners are Baker College, Wright State University, and the College of Lake County with other participating institutions such as: Cincinnati State Technical and Community College, Minnesota State College Southeast Technical, Anoka Ramsey Community College, Central Community College, and the Columbia Area Career Center.

MPEC was established with six primary goals. These goals and their corresponding objectives are:

Goal 1 - Establish education programs and strategies to address industry needs for photonics technicians.

- Seek industry input on photonics program and curricula development.

- Mentor and assist colleges to establish photonics programs and/or infuse photonics coursework into existing programs.

- Develop add-on courses and modules to teach the specific skills and competencies needed by employers in participant colleges’ geographic areas.

\section{Goal 2 - Provide national leadership for technician education in laser-assisted advanced manufacturing.}

- Design, equip and operate a pilot specialty laboratory for laser assisted manufacturing and materials processing at IHCC.

- Develop and offer a hybrid course on laser assisted manufacturing and materials processing and make it available nationwide.

- Host five-day professional development workshops for U.S. postsecondary educators on laser assisted manufacturing and materials processing at the specialty lab.

- Evaluate the regional photonics specialty laboratory pilot and explore replicating the pilot at other colleges throughout the U.S.

Goal 3 - Strengthen educational institutions' ability to recruit, train and advance photonics students including women, minorities and veterans.

- Increase female photonics student recruitment and retention at MPEC institutions.

- Coordinate the development of articulation agreements. 
- Act as a regional clearinghouse for organizing photonics internships, job shadowing and other industry field experience opportunities for students and educators.

- Grow the number of Hispanics and other minorities enrolled in photonics programs at two-year institutions.

- Assist veterans to identify, enroll and complete a two-year photonics technician program.

- Provide professional development for Project Coordinators.

\section{Goal 4 - Collaborate with partner educational institutions and employers to promote photonics in the K-14 space to fill the student "pipeline."}

- Increase the number of high school students entering photonics programs at two-year colleges.

- Broaden photonics awareness and create support at the K-12 level.

- Create interest in photonics-related careers among K-12 students.

\section{Goal 5 - Develop customized on-site photonics education workshops and provide to companies and colleges.}

- Survey photonics technician employers in the Midwest to determine their incumbent employee education/training needs.

- Assist companies to provide professional development to their photonics technicians.

- Provide professional development to postsecondary educators.

\section{Goal 6 - Evaluate educational materials and share best practices.}

- Assess photonics education initiatives (in conjunction with OP-TEC).

- Share best practices in photonics educations by presenting breakout sessions and hosting exhibits at state, regional and/or national conferences.

In its first year of existence MPEC has made varying degrees of progress towards achieving the objectives of the grant project. Activities took place at the lead college and the principal partners supporting the objectives as follows:

Goal 1. Establish education programs and strategies to address industry needs for photonics technicians:

Industry advisory committee meetings were hosted at IHCC and partner colleges to seek input on photonics program and curricula development. A review of the 2-year program curriculum revealed that the core courses and major courses were already on target and simply needed some minor modifications while the program name was due for an update. The program name was changed from Laser/Electro-Optics Technology to Laser \& Optics Technology because of the increased emphasis on optics in the field of photonics. Two new optional courses were added to the program in order to broaden student opportunities. LEO932 Internship was added in order to allow students to earn college credit while working at an internship in industry. BUS128 Foundation to Entrepreneurship was added to provide an entrepreneurial background for students that may consider starting their own businesses after graduation.

A survey of 950 Midwest employers was conducted to determine technical skills and abilities required for photonics technicians. The 54 respondents to date replied with the following response data in Tables 1-8: 
Table 1: Importance of photonics/laser technicians understanding of principles of light and fundamentals of optics.

\begin{tabular}{|c|c|c|c|c|c|}
\hline $\begin{array}{l}\text { Question 1: } \\
\text { How important is it for photonics/laser technicians to } \\
\text { understand the following principles of light and } \\
\text { fundamentals of optics? }\end{array}$ & 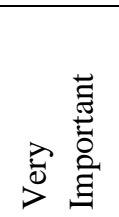 & $\begin{array}{l}\vec{\Xi} \\
\text { : } \\
\text { 官 }\end{array}$ & 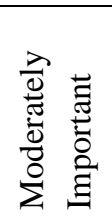 & 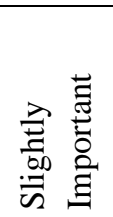 & 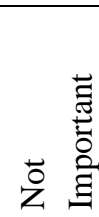 \\
\hline Nature, properties \& characteristics of light & $48.1 \%$ & $31.5 \%$ & $18.5 \%$ & $1.9 \%$ & $0.0 \%$ \\
\hline Characteristics of coherent/non-coherent light & $43.4 \%$ & $37.7 \%$ & $13.2 \%$ & $3.8 \%$ & $1.9 \%$ \\
\hline Geometric (ray) optics & $33.3 \%$ & $40.7 \%$ & $14.8 \%$ & $7.4 \%$ & $3.7 \%$ \\
\hline Physical (wave) optics & $28.3 \%$ & $35.8 \%$ & $20.8 \%$ & $11.3 \%$ & $3.8 \%$ \\
\hline Linear \& Non-linear optics & $28.3 \%$ & $37.7 \%$ & $18.9 \%$ & $11.3 \%$ & $3.8 \%$ \\
\hline Optical mounts \& supports & $50.9 \%$ & $39.6 \%$ & $9.4 \%$ & $0.0 \%$ & $0.0 \%$ \\
\hline Optical components \& usage (lenses, mirrors, etc.) & $63.0 \%$ & $33.3 \%$ & $3.7 \%$ & $0.0 \%$ & $0.0 \%$ \\
\hline Optical fibers & $27.8 \%$ & $44.4 \%$ & $25.9 \%$ & $1.9 \%$ & $0.0 \%$ \\
\hline
\end{tabular}

Table 2: Importance of applied mathematics skills for photonics/laser technicians.

\begin{tabular}{|c|c|c|c|c|c|}
\hline $\begin{array}{l}\text { Question 2: } \\
\text { How important are the following applied mathematics } \\
\text { skills for photonics/laser technicians? }\end{array}$ & 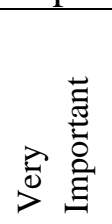 & 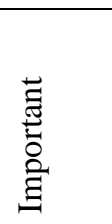 & 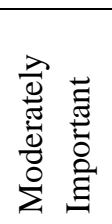 & 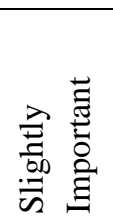 & 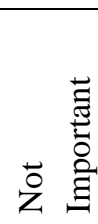 \\
\hline Fundamental Math & $77.8 \%$ & $16.7 \%$ & $3.7 \%$ & $1.9 \%$ & $0.0 \%$ \\
\hline Algebra & $38.9 \%$ & $22.2 \%$ & $24.1 \%$ & $11.1 \%$ & $3.7 \%$ \\
\hline Geometry \& Trigonometry & $35.2 \%$ & $35.2 \%$ & $22.2 \%$ & $7.4 \%$ & $0.0 \%$ \\
\hline Read Scale Drawings & $64.2 \%$ & $26.4 \%$ & $9.4 \%$ & $0.0 \%$ & $0.0 \%$ \\
\hline Understanding Graphs \& Charts & $50.0 \%$ & $40.7 \%$ & $7.4 \%$ & $1.9 \%$ & $0.0 \%$ \\
\hline Units of Measurement & $83.3 \%$ & $16.7 \%$ & $0.0 \%$ & $0.0 \%$ & $0.0 \%$ \\
\hline Understanding Precision, Accuracy \& Tolerance & $83.3 \%$ & $16.7 \%$ & $0.0 \%$ & $0.0 \%$ & $0.0 \%$ \\
\hline
\end{tabular}

Table 3: Importance of photonics/laser technicians understanding of laser system fundamentals.

\begin{tabular}{|c|c|c|c|c|c|}
\hline $\begin{array}{l}\text { Question 3: } \\
\text { How important is it for photonics/laser technicians to } \\
\text { understand the following laser system fundamentals? }\end{array}$ & 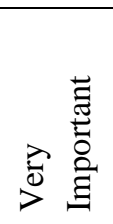 & 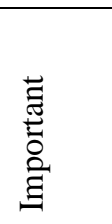 & 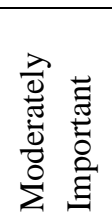 & 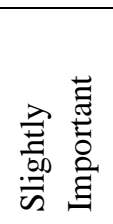 & 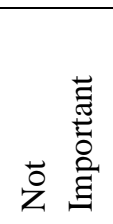 \\
\hline Laser design & $22.6 \%$ & $41.5 \%$ & $18.9 \%$ & $17.0 \%$ & $0.0 \%$ \\
\hline Types or characteristics of lasers & $28.3 \%$ & $49.1 \%$ & $13.2 \%$ & $9.4 \%$ & $0.0 \%$ \\
\hline Controlling or modifying a laser beam & $56.6 \%$ & $24.5 \%$ & $11.3 \%$ & $7.5 \%$ & $0.0 \%$ \\
\hline Power supplies & $34.0 \%$ & $34.0 \%$ & $20.8 \%$ & $11.3 \%$ & $0.0 \%$ \\
\hline Cooling systems & $24.5 \%$ & $37.7 \%$ & $24.5 \%$ & $7.5 \%$ & $5.7 \%$ \\
\hline Mechanical systems \& components & $39.6 \%$ & $35.8 \%$ & $18.9 \%$ & $5.7 \%$ & $0.0 \%$ \\
\hline Pneumatic systems \& components & $20.0 \%$ & $26.0 \%$ & $38.0 \%$ & $6.0 \%$ & $10.0 \%$ \\
\hline
\end{tabular}


Table 4: Importance of photonics/laser technicians' skills regarding laser systems \& devices and optical systems \& components.

\begin{tabular}{|c|c|c|c|c|c|}
\hline $\begin{array}{l}\text { Question 4: } \\
\text { How important is it for photonics/laser technicians to } \\
\text { have the following skills regarding laser systems \& } \\
\text { devices and optical systems \& components? }\end{array}$ & > & 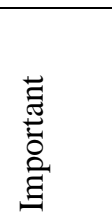 & 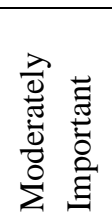 & 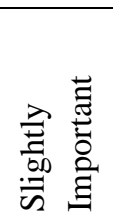 & 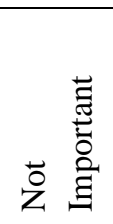 \\
\hline Characterize a laser output using necessary equipment & $57.4 \%$ & $24.1 \%$ & $11.1 \%$ & $5.6 \%$ & $1.9 \%$ \\
\hline Build and assemble laser systems & $37.0 \%$ & $25.9 \%$ & $11.1 \%$ & $14.8 \%$ & $11.1 \%$ \\
\hline Install, test and calibrate laser systems & $64.8 \%$ & $20.4 \%$ & $5.6 \%$ & $5.6 \%$ & $3.7 \%$ \\
\hline Program and operate laser systems & $59.3 \%$ & $24.1 \%$ & $3.7 \%$ & $9.3 \%$ & $3.7 \%$ \\
\hline Troubleshoot and repair laser systems & $63.0 \%$ & $18.5 \%$ & $7.4 \%$ & $3.7 \%$ & $7.4 \%$ \\
\hline Build, clean \& align various optical systems & $83.3 \%$ & $13.0 \%$ & $1.9 \%$ & $0.0 \%$ & $1.9 \%$ \\
\hline Use basic optical instruments (e.g., autocollimator, etc.) & $57.4 \%$ & $25.9 \%$ & $7.4 \%$ & $5.6 \%$ & $3.7 \%$ \\
\hline Clean laser grade optics to technical specifications & $75.5 \%$ & $24.5 \%$ & $0.0 \%$ & $0.0 \%$ & $0.0 \%$ \\
\hline
\end{tabular}

Table 5: Importance of photonics/laser technicians’ basic technical and electronic skills. Question 5:

How important is it for photonics/laser technicians to have the following basic technical and electronic skills?

Analyze analog/digital circuits using probes, pulse generators, oscilloscopes, digital multi-meters, etc.

Operate an assortment of instruments, e.g., power supplies, frequency generators, recording devices, etc.

Read \& interpret electronic/mechanical/optical drawings \& schematics.

Identify \& work within project constraints

\begin{tabular}{|c|c|c|c|c|}
\hline 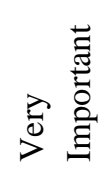 & 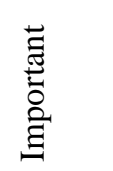 & 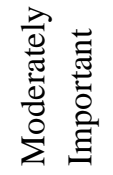 & 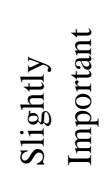 & 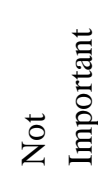 \\
\hline $27.8 \%$ & $33.3 \%$ & $22.2 \%$ & $14.8 \%$ & $1.9 \%$ \\
\hline $37.0 \%$ & $27.8 \%$ & $22.2 \%$ & $13.0 \%$ & $0.0 \%$ \\
\hline $53.7 \%$ & $38.9 \%$ & $3.7 \%$ & $3.7 \%$ & $0.0 \%$ \\
\hline $42.6 \%$ & $42.6 \%$ & $13.0 \%$ & $1.9 \%$ & $0.0 \%$ \\
\hline
\end{tabular}

Table 6: Importance of photonics/laser technicians understanding of laser assisted processes.

\section{Question 6:}

How important is it for photonics/laser technicians to understand the following laser assisted processes?

Laser welding

Laser cutting

Laser scoring \& drilling

Laser surface treatment

Laser additive manufacturing (e.g. 3D printing)

Laser micromachining

Laser marking \& engraving

\begin{tabular}{|c|c|c|c|c|}
\hline 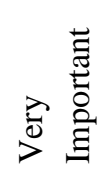 & 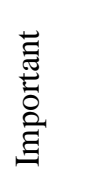 & 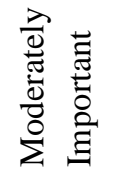 & 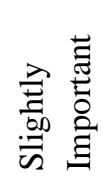 & 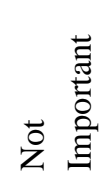 \\
\hline $20.8 \%$ & $15.1 \%$ & $28.3 \%$ & $15.1 \%$ & $20.8 \%$ \\
\hline $28.8 \%$ & $13.5 \%$ & $25.0 \%$ & $17.3 \%$ & $15.4 \%$ \\
\hline $17.3 \%$ & $17.3 \%$ & $25.0 \%$ & $17.3 \%$ & $23.1 \%$ \\
\hline $9.4 \%$ & $20.8 \%$ & $34.0 \%$ & $13.2 \%$ & $22.6 \%$ \\
\hline $11.3 \%$ & $22.6 \%$ & $24.5 \%$ & $17.0 \%$ & $24.5 \%$ \\
\hline $11.3 \%$ & $17.0 \%$ & $24.5 \%$ & $24.5 \%$ & $22.6 \%$ \\
\hline $13.2 \%$ & $18.9 \%$ & $34.0 \%$ & $22.6 \%$ & $11.3 \%$ \\
\hline
\end{tabular}


Table 7: Importance of photonics/laser technicians understanding of laser related safety information.

\begin{tabular}{|c|c|c|c|c|c|}
\hline $\begin{array}{l}\text { Question 7: } \\
\text { How important is it for photonics/laser technicians to } \\
\text { understand the following laser related safety information? }\end{array}$ & 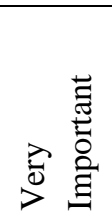 & 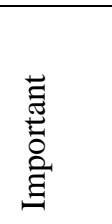 & 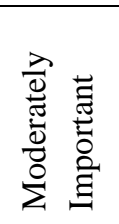 & 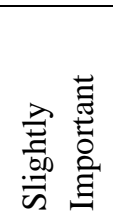 & 泀蓄 \\
\hline Laser safety concepts (Hazards, effects, exposure, etc.) & $81.5 \%$ & $11.1 \%$ & $3.7 \%$ & $1.9 \%$ & $1.9 \%$ \\
\hline Laser safety checks according to ANSI standards & $64.8 \%$ & $16.7 \%$ & $14.8 \%$ & $1.9 \%$ & $1.9 \%$ \\
\hline Electrical considerations & $52.8 \%$ & $32.1 \%$ & $11.3 \%$ & $3.8 \%$ & $0.0 \%$ \\
\hline Chemical \& material safety (MSDS) & $42.6 \%$ & $42.6 \%$ & $9.3 \%$ & $5.6 \%$ & $0.0 \%$ \\
\hline Lockout/Tag out procedures & $57.4 \%$ & $29.6 \%$ & $3.7 \%$ & $9.3 \%$ & $0.0 \%$ \\
\hline OSHA requirements & $44.4 \%$ & $40.7 \%$ & $7.4 \%$ & $7.4 \%$ & $0.0 \%$ \\
\hline
\end{tabular}

Table 8: Importance of life skills for photonics/laser technicians.

\begin{tabular}{|c|c|c|c|c|c|}
\hline $\begin{array}{l}\text { Question 8: } \\
\text { How important are the following life skills for } \\
\text { photonics/laser technicians? }\end{array}$ & 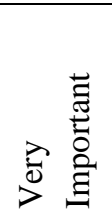 & 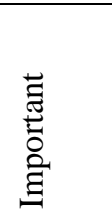 & 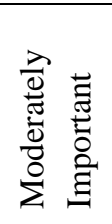 & 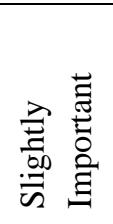 & 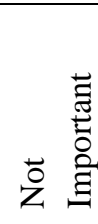 \\
\hline Problem Solving (Analytical thinking, complex reasoning) & $70.4 \%$ & $27.8 \%$ & $1.9 \%$ & $0.0 \%$ & $0.0 \%$ \\
\hline Initiative (Self-starter, productive) & $64.2 \%$ & $34.0 \%$ & $1.9 \%$ & $0.0 \%$ & $0.0 \%$ \\
\hline Prioritizing/Planning/Organizing & $51.9 \%$ & $37.0 \%$ & $11.1 \%$ & $0.0 \%$ & $0.0 \%$ \\
\hline Professionalism (Responsible, accountable, dependable) & $73.6 \%$ & $24.5 \%$ & $1.9 \%$ & $0.0 \%$ & $0.0 \%$ \\
\hline Integrity (Honesty, ethics, fairness) & $87.0 \%$ & $13.0 \%$ & $0.0 \%$ & $0.0 \%$ & $0.0 \%$ \\
\hline Attitude/Cooperation & $90.7 \%$ & $9.3 \%$ & $0.0 \%$ & $0.0 \%$ & $0.0 \%$ \\
\hline Communications (Verbal, written, collaborative, teamwork) & $75.9 \%$ & $20.4 \%$ & $3.7 \%$ & $0.0 \%$ & $0.0 \%$ \\
\hline Attendance/Punctuality & $72.2 \%$ & $25.9 \%$ & $1.9 \%$ & $0.0 \%$ & $0.0 \%$ \\
\hline
\end{tabular}

The results of the industry survey revealed no real surprises in terms of the technical expertise required for laser/photonics technicians. As would be expected, the need for laser safety awareness and procedures rated highly among most respondents. Interestingly, the need for the majority of the life skills were almost all rated as important or very important.

An educational institution survey for MPEC partner colleges was conducted to obtain input on institutional photonics program/courses and institutional assistance needed. The survey indicated that all partner colleges were in need of some level of assistance. The primary needs identified by partners were assistance with curriculum development, laboratory equipment selection, professional development opportunities for faculty, laboratory activity development, recruitment strategies, articulations, internships, and industry surveys.

MPEC has worked with William Penn University to add "Photonics Concepts" as an elective course for Industrial Technology students. The new course has been offered during the spring term of 2016. In an effort to support colleges in starting courses or programs, MPEC has mentored and assisted additional institutions such as Southeast Community College (SCC) of Nebraska, State Technical College (STC) and Columbia Area Career Center (CACC) of 
Missouri, and Johnson County Community College (JCCC) of Kansas as they considered the feasibility of establishing photonics programs or photonics certificates and/or infusing photonics coursework into existing programs. MPEC has provided additional technical assistance to Columbia Area Career Center (CACC) of Missouri as they work to expand their photonics programs to include evening offerings of photonics certificates. All of these institutions have visited IHCC for laboratory tours and in-depth discussions of curriculum design, laboratory equipment needs, graduate job placement and other challenges to program startup. Each institution has received a follow-up visit from MPEC for additional on-site technical assistance. STC plans to add two or three photonics courses with a certificate and is considering an AAS program offering in the future. JCCC and SCC are both moving forward with the addition of new photonics courses. JCCC is planning the development of a three course photonics certificate and SCC is planning the development of an Associate of Applied Science (AAS) degree. MPEC also assisted OP-TEC with technical support for Lake Washington Institute of Technology through an on-site visit.

Goal 2. Provide national leadership for technician education in laser-assisted advanced manufacturing:

MPEC visited laser equipment vendors while attending expositions and tradeshows such as Photonics West Exposition, Lasers for Manufacturing Event, and Medical Device Manufacturers Expo. After extensive research on laser welding and other laser materials processing equipment, MPEC has ordered a Trumpf TruLaser Station 5005 welding system for a pilot specialty laboratory for laser assisted manufacturing and materials processing at IHCC. Delivery and installation is planned for the spring of 2016.

In year 2, MPEC is developing a hybrid course on laser assisted manufacturing and materials processing in conjunction with the laboratory equipment that has been purchased. MPEC trainer Frank Reed has attended Laser Weld training through HDE Technologies, Inc. in preparation for development of the hybrid course. MPEC plans to host five-day professional development workshops for postsecondary educators and others in laser assisted manufacturing and materials processing utilizing the new laboratory equipment.

MPEC hosted a five-day professional development laboratory activity at IHCC for 11 educators in collaboration with OP-TEC (The National Center for Optics and Photonics Education). The online theory portion of this "Fundamentals of Light and Lasers" course was offered through OP-TEC and the laboratory portion of the workshop was provided on campus at IHCC.

Goal 3. Strengthen educational institutions’ ability to recruit, train and advance photonics students including women, minorities and veterans:

As part of the initiative to increase female photonics student recruitment and retention at IHCC and partner institutions, an MPEC team of six IHCC faculty and staff participated in the IWITTS (Institute for Women in Trades, Technology, and Science) NSF-Funded Women Tech educators Online Training Fellowship, “A proven System for Increasing the Number of Female Students in Your STEM Program”. An internal recruitment and retention plan was developed for IHCC as a result of this training and then shared with MPEC partner colleges and other institutions that participated in the training. As a result of the IWITTS training, IHCC created and hosted a "Women in Engineering STEM Day" for high school girls. This first year event was held on 
May 13, 2015. As the keynote speaker, a female John Deere engineer spoke to the students about her career path and eight girls participated in hands-on activities at IHCC. Another result of the IWITTS training, included the promotion and support of a breakout session presentation on "Women in Advanced Manufacturing" at IHCC’s annual Counselor Day.

MPEC partner Cincinnati State Technical and Community College (CSTCC) planned and hosted a Women Tech Educators Training on campus in Cincinnati, $\mathrm{OH}$ on recruitment and retention through the Institute for Women in Trades, Technology, and Science. Ten representatives from four of the MPEC partner colleges participated in the workshop along with 13 other participants from the Cincinnati area schools.

MPEC worked with Buena Vista University (BVU) to coordinate the development of a new transfer articulation agreement between and IHCC and BVU. The new agreement is for transfer from an Associate of Applied Science Degree program in IHCC Advanced Technology Programs to a Bachelor of Applied Science Program at BVU. This articulation includes multiple programs such as Laser \& Optics Technology and other technical programs so the broader impact of MPEC has benefitted other programs at IHCC. CSTCC has been working with the Northern Kentucky University (NKU) on an articulation agreement for CSTCC's laser courses to be included within the NKU Mechatronics program. The College of Lake County in Grays Lake, Illinois has been working with Purdue University on an articulation agreement for their Photonics AAS program. MPEC has also been working with William Penn University for a transfer articulation agreement from IHCC's Laser \& Optics Technology program into a BA degree in Technology Management with an emphasis in leadership.

MPEC worked with MUSCO Lighting to develop an internship agreement that can benefit students from multiple programs including Laser and Optics, Robotics/Automation, and Electronics Engineering Technology. MPEC organized or sponsored photonics industry tours/field experience opportunities for students and educators at six companies across the United States including Preco, Inc., National Ignition Facility at Lawrence Livermore National Laboratory, Coherent, Radiance, Spectra-Physics, and John Deere.

In support of K-12 educator professional development, MPEC sponsored the transportation for a company tour for 23 educators to visit Musco Lighting during an "Educators in the Workplace" professional development. The workshop also included an MPEC presentation on photonics technology and career opportunities, additional information sessions and company tours, IHCC campus and laboratory tours, and a Business \& Industry Representative Panel discussion.

MPEC also attended a Home Base Iowa workshop on Demystifying Military Credit Evaluations "The Rigor of the ACE Review Process" in order to better assist veterans in transferring into technical programs.

MPEC supported multiple professional development opportunities for Project Coordinators at MPEC institutions including Laser Weld Training, Laser Safety Officer Training, High Impact Technology Exchange Conference, Strategies in Light/LED show, Lasers for Manufacturing Event and Summit, Photonics West, National Coalition of Advanced Technology Centers conference, and the NSF-Advanced Technology Education Principal Investigator's conference. 
Six MPEC institution instructors have completed the Laser Institute of America's Laser Safety Officer training.

Goal 4. Collaborate with partner educational institutions and employers to promote photonics in the K-14 space to fill the student "pipeline":

With MPEC support, IHCC sponsored and hosted a group of 18 Columbia Area Career Center (CACC) students, one faculty member and one administrator for a two-day college immersion experience. The experience included a campus orientation and tour, admissions and financial aid presentations, Laser program and Laser Club presentations, career and educational opportunity presentations, and a half-day hands-on laboratory activity. One of the key elements that enhanced the experience was the interaction between college and career center students. The CACC students were fully immersed in campus activities and integrated into the Laser laboratory along with college students for the hands-on laboratory experience. A best practice presentation about this activity was shared in breakout sessions at the HI-TEC conference and the NCATC conference.

MPEC partnered with LASER-TEC (Southeast Regional Center) and OP-TEC to host a hands-on laser/photonics exhibit at a special event called Wonders of Light: Family Science Fun in Washington, D.C. Over 500 kids and their families attended this event that was sponsored by NSF in support of the 2015 International Year of Light and Light Based Technologies. MPEC also hosted a laser/photonics exhibit at a regional "STEM Festival" that was attended by over 350 students and family members. The laser exhibit was very popular among attendees and included a laser light show with popular music.

MPEC has several direct linkages to the K-12 schools within regions of each institution. MPEC Co-PI, Dr. Larry Dosser, Senior Fellow for Technology Advancement at the Center for Manufacturing Sciences of Wright State University has been working with the Dayton Regional STEM School to develop a laser/optics/manufacturing laboratory. Dr. Dosser plans to develop and incorporate special topics on materials processing for the laboratory. The College of Lake County has a High School Technology Campus located adjacent to the CLC campus. Among the course offerings is a Laser/Photonics/Optics program for dual credit. Baker College and IHCC offer dual-credit photonics courses for high school students on their campuses in order to "fill the student pipeline”.

MPEC also partnered, hosted, presented, or exhibited on photonics awareness activities to create interest for over 9286 students and 3000+ community members including the following activities:

- $8^{\text {th }}$ Grade Career Day activities - 97 students

- Senior Day activity - 24 students

- Junior Day activity - 24 students

- Gear-Up Day activity - 39 students

- GEMS Camp activity - 38 students

- 3D Printing Camp activity - 16 students

- Robotics Camp activity - 15 students

- Tech Camp activity - 18 students

- STEM Academy presentation - 25 students 
- Almont Middle School presentation - 140 students

- Almont Middle School Career Fair - 300 students

- Manufacturing Days - 450+ students

- Discover STEM - 8000+ students

- Senior Engineering conference - 100+ students

- Festival of Lights - 3000+ community members

Goal 5. Develop customized on-site photonics education workshops and provide to companies and colleges:

MPEC and college partners have developed Photonics Workshops and provided one-day professional development opportunities for 31 secondary and postsecondary educators as follows:

- IITEA (Iowa Industrial Technology Education Conference) conference - 9 participants

- Kansas Center for Career and Technical Education - 8 participants

- Baker College Photonics Workshop - 14 participants

As a result of their participation in these workshops, several of the participants are planning to implement photonics lessons into their classrooms. Additional Photonics Workshops are being scheduled in a multiple states throughout the Midwest.

Just after MPEC was established, an immediate industry request led to the development of a customized "Fundamentals of Lighting" course. This curriculum includes broader photonics topics such as luminaires, controls, lighting metrics, photometry, codes, design, and light sources. This course will tentatively be offered to the company employees in fall of 2016.

6. Evaluate educational materials and share best practices:

MPEC partners have worked with OP-TEC to assess photonics education initiatives such as the newly developed e-book "Fundamentals of Light and Lasers" and assisted with the recently revised OP-TEC Course 2 laboratory activities for "Laser Systems and Applications". MPEC partner Baker College has also pilot tested the OP-TEC textbooks for "Quality Assurance and Precision Optics" and "Metrology of Optical Systems".

MPEC partners have shared best practices in photonics education with dozens of attendees by presenting informational breakout sessions at events such as the HI-TEC Conference, National Coalition of Advanced Technology Centers Conference, Educators in the Workplace, Iowa Association of Career and Technical Education Conference, NSF-ATE PI conference, Indiana School Counselors Association Conference, Michigan School Counselors Association Conference and IHCC Counselor Day.

MPEC partners have hosted exhibits or poster sessions at conferences and expositions including the National Coalition of Advanced Technology Centers conference, Regional Entrepreneurship Center grand opening, STEM Careers Conference for Counselors \& Teachers, Photonics West Conference, AACC Conference, HI-TEC Conference, ASEE Conference and the NSF-ATE PI Conference. 


\section{Conclusions}

This paper describes the historical perspective and rationale for the development of the Midwest Photonics Education Center. The primary goals are expressed along with selected strategies for accomplishing those goals. In support of the strategies, ongoing or completed activities are described. Photonics is a key technology that enables other industry sectors with a plethora of new and emerging applications. The main focus of MPEC is in laser materials processing in advanced manufacturing but the broader impact of the center reaches into fields such as lighting, medical, communications, military, and others. The efforts of MPEC are designed to be in collaboration with the work of other NSF centers including OP-TEC and LASER-TEC.

\section{Acknowledgement}

The project described in this paper is supported in part by the National Science Foundation Advanced Technological Education program, under Grant DUE\# 1400561 "Midwest Photonics Education Center.”

Any opinions, findings, and conclusions or recommendations expressed in this material are those of the authors and do not necessarily reflect the views of the National Science Foundation.

\section{Bibliography}

1. http://www.light2015.org/Home/Event-Programme.html?tab=1. Accessed Jan. 11, 2016.

2. http://www.aimphotonics.com/. Accessed Jan. 11, 2016.

3. http://www.op-tec.org/index.php. Accessed Jan. 11, 2016.

4. http://www.op-tec.org/resources/industry-demand-report. Accessed Jan. 30, 2016.

5. http://www.mi-light.org. Accessed Jan. 11, 2016. 